\title{
EDITORIAL
}

\section{Discriminación múltiple en el mercado laboral: ¿qué opciones tiene una mujer discapacitada de encontrar un puesto de trabajo?}

\author{
Eva María BlázQuez Agudo
}

Directora de Femeris. Universidad Carlos III de Madrid

Orcid id: 0000-0002-8214-1960

doi: https://doi.org/10.20318/femeris.2018.4070

Se entiende por discriminación múltiple aquella situación de desventaja social derivada de la concurrencia en una misma persona o grupo social de más de un factor que puede dar lugar a discriminación. Muchos son los colectivos y los factores que se pueden combinar, pero en este editorial se quiere poner en evidencia la que sufren las mujeres, cuando además suman otro factor discriminatorio.

En 1995, en la 4ํㅡㄹ Conferencia Mundial sobre Mujeres en Beijing se declaró que las barreras múltiples han impedido a las mujeres avanzar en la igualdad, completándose el primer reconocimiento internacional de esta situación en la Declaración de Durban en 2001 en el marco de la Conferencia de Naciones Unidas contra el racismo, donde se interrelacionan dos factores: el género y la etnia.

Si de forma general las mujeres sufren discriminación en el mercado laboral, esta desventaja aumenta exponencialmente en el supuesto de que, además, añadan otro factor de riesgo tal como el origen étnico, la religión, la discapacidad o la edad, entre otras. Si las trabajadoras son un grupo especialmente vulnerable al trato desigual, cuando se combina su situación con otro factor discriminante, se multiplican las posibilidades de ser excluidas o discriminadas en el mundo laboral.

Centrémonos en la situación de la mujer discapacitada, ¿en cuánto aumentará su dificultad en conseguir insertarse plenamente en el mercado laboral?

Analicemos los datos del mercado laboral español. En el último estudio publicado por el INE "El empleo de las personas con discapacidad" en 2016 se pone de manifiesto que el $35,2 \%$ de las personas con discapacidad oficialmente reconocida eran activas. Aunque el número se ha elevado 1,3\% respecto al año anterior, no obstante, la tasa de actividad sigue siendo un 42,8 \% inferior a la de la población sin discapacidad. Conclusio- 
nes similares obtenemos del examen de la tasa de desempleo. La tasa de desempleo entre trabajadores con discapacidad es $9,1 \%$ superior para las personas con discapacidad en comparación con las que no la sufren.

Si hacemos el análisis desde el punto de vista de la perspectiva de género, las posibilidades de exclusión se extreman. Así, de las 462.000 personas con discapacidad ocupadas en 2016, 267.500 eran hombres (el 57,9\%) y 194.500 mujeres (el 42,1\%). También en la tasa de paro de las mujeres con discapacidad se puede observar una evolución similar. En este caso, el 29,3\% es la tasa de paro de las mujeres frente al 28,1\% de los hombres.

No obstante, esta diferencia es mayor si se tiene en cuenta que según datos de la Confederación Española de Personas con Discapacidad Física y Orgánica, el 60\% de las personas con discapacidad son mujeres. De esta forma, aunque hay más mujeres discapacitadas que hombres, en todo el colectivo hay más hombres en activo.

En definitiva, el porcentaje de personas con discapacidad en el mercado laboral es inferior a las personas que no se encuentran en esta situación, y si estas personas son mujeres, la exclusión se hace más intensa.

Así, es fácil imaginar que si las trabajadoras, en general, sufren la brecha salarial que, consecuentemente, provoca la desprotección social o con suerte, la obtención de pensiones con cuantías no suficientes; la contratación temporal; los contratos a tiempo parcial, en muchas ocasiones sin ser una opción voluntaria, sino dirigida por el propio mercado; así como la doble jornada laboral; en el caso de las trabajadoras con discapacidad todas estas cuestiones se acentuarán, llevando a este colectivo hacia una situación de especial vulnerabilidad.

Así, por ejemplo, en el colectivo de las mujeres con discapacidad la brecha salarial es todavía mayor que en el supuesto de las trabajadoras en general. En 2016 el salario medio de la mujer con discapacidad es más de 3.057 euros inferior al del varón, al igual que un $12 \%$ menor que las mujeres sin discapacidad de acuerdo con la ODISMET.

Pero, siendo grave esta situación, el problema mayor de las mujeres con discapacidad no es como desarrollan su actividad laboral, sino que en la mayoría de los casos se clasifican como inactivas. De acuerdo con una encuesta realizada por el INE, IMSERSO y Fundación ONCE, el 76,41\% de este colectivo se clasifica como tal. En la misma línea, en la Encuesta de la población en edad laboral discapacitada y mujer. (ODISMET, 2016) se indica que un 33\% de las mujeres en esta situación están activas, mientras que casi un 67\% están inactivas. Indicando que la ratio de mujeres inactivas se triplica en el supuesto del colectivo de mujeres discapacitadas. Es decir, ni siquiera tratan de acceder a una actividad remunerada para conseguir su independencia económica.

El tema del alto porcentaje de inactividad se relaciona directamente con la carencia de formación. Así, en 2015 cerca del 30\% de las mujeres con discapacidad no habían finalizado los estudios primarios, y solo el 17,1\% tenía estudios superiores (la mitad del porcentaje de las mujeres sin discapacidad) de acuerdo con las estadísticas sobre nivel formativo de las mujeres con discapacidad, Datos desde la perspectiva de género, ODISMET, Fundación Once.

La Convención Internacional sobre los Derechos de las Personas con Discapacidad ha hecho un llamamiento especial sobre la necesidad de prohibir la discriminación por 
motivos de discapacidad en el contexto del empleo. Señala la necesidad de que se les apliquen condiciones de trabajo justas y favorables (remuneración, condiciones de trabajo seguras y saludables); se asegure sus derechos laborales y sindicales; su acceso a formación, a la promoción profesional y rehabilitación profesional; la promoción de oportunidades empresariales; se creen incentivos dirigidos a personas con discapacidad en el sector público y privado; así como se realicen ajustes razonables en el lugar de trabajo.

Todas estas indicaciones generales deberán tenerse en cuenta aún más en el caso de las mujeres con discapacidad, dado que en su caso la discriminación sufrida en el mercado laboral será doble y, como ya se ha señalado, serán más susceptibles de sufrir la exclusión en el trabajo.

De hecho, si bien es verdad que se ha producido un aumento progresivo de los contratos laborales para las personas discapacitadas en los últimos años, sin embargo, el incremento es exponencialmente superior en el supuesto de los hombres.

En conclusión, es preciso regular incentivos en el mercado laboral para animar a la contratación de las mujeres con discapacidad, que por el momento conforman un colectivo especialmente vulnerable, en condiciones optimas con el fin de asegurar su independencia económica durante la etapa laboral y, consecuentemente, una protección social adecuada en el momento de la finalización de su período activo.

Claramente los porcentajes legalmente obligatorios de contratación de trabajadores con discapacidad no promueven la contratación femenina, ni tampoco lo hacen la creación de centros especiales de trabajo para este colectivo. Si bien es verdad que existen asimismo incentivos económicos, especialmente reducciones y bonificaciones en las cotizaciones a la Seguridad Social, que se incrementan en el supuesto de la contratación de mujeres, parece que tampoco este elemento está siendo decisivo en el aumento del número de mujeres discapacitadas activas.

Obviamente se precisan políticas públicas completas que traten el problema en su conjunto. Es preciso partir de la necesidad de formación de este colectivo. Solo de esta forma se preparará a las mujeres para salir del grupo de los inactivos y tratar de buscar trabajo. A partir de este punto de partida, será preciso crear medidas generales que incentiven la contratación, que además de las clásicas reducciones en la cotización, puedan ayudar a este objetivo, partiendo de las discriminaciones generales que sufren las mujeres que luego se agravan si existe otro factor como el de la discapacidad. Por ejemplo, el fomento de la contratación indefinida y a tiempo completo como forma de garantizar un salario digno; las campañas de concienciación, tanto de los empresarios, como del resto de los trabajadores, sobre el valor del trabajo de estas mujeres al mismo nivel que los demás; y el desarrollo de medidas de formación permanente adaptadas a sus necesidades; entre otras. 